\title{
Spectre du Brocken depuis les falaises de Moher
}

Ce magnifique spectre a été photographié par Sean Tomkins du haut des falaises de Moher (230 m de haut) un jour de brouillard. Celui-ci est en cours de dissipation au moment de la prise de vue, ce qui permet de voir le spectre à distance, avec la verte côte d'Irlande et au fond la tour O'Brien.

Cette photo a reçu le troisième prix du jury de l'Europhotometeo'12 dont vous avez pu voir le deuxième dans le numéro précédent de la revue La Météorologie.

Vous pouvez encore voir les 400 photos du concours sur le site de l'European Meteorological Society. 


\section{COLLOQUE INTERNATIONAL INTERNATIONAL SYMPOSIUM}

\section{météo etclimat}

\section{$10^{\circ}$ tory 111 it timat}

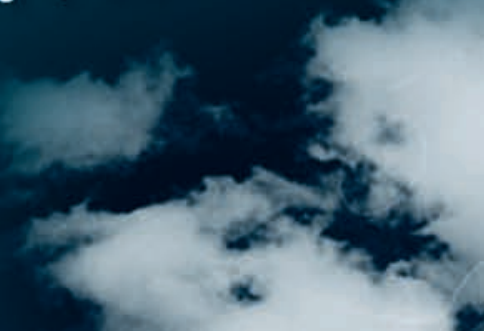

Agir face cun wisques The Weather and Climate météo-climatiques: outils et Risks Challenge: Tools and
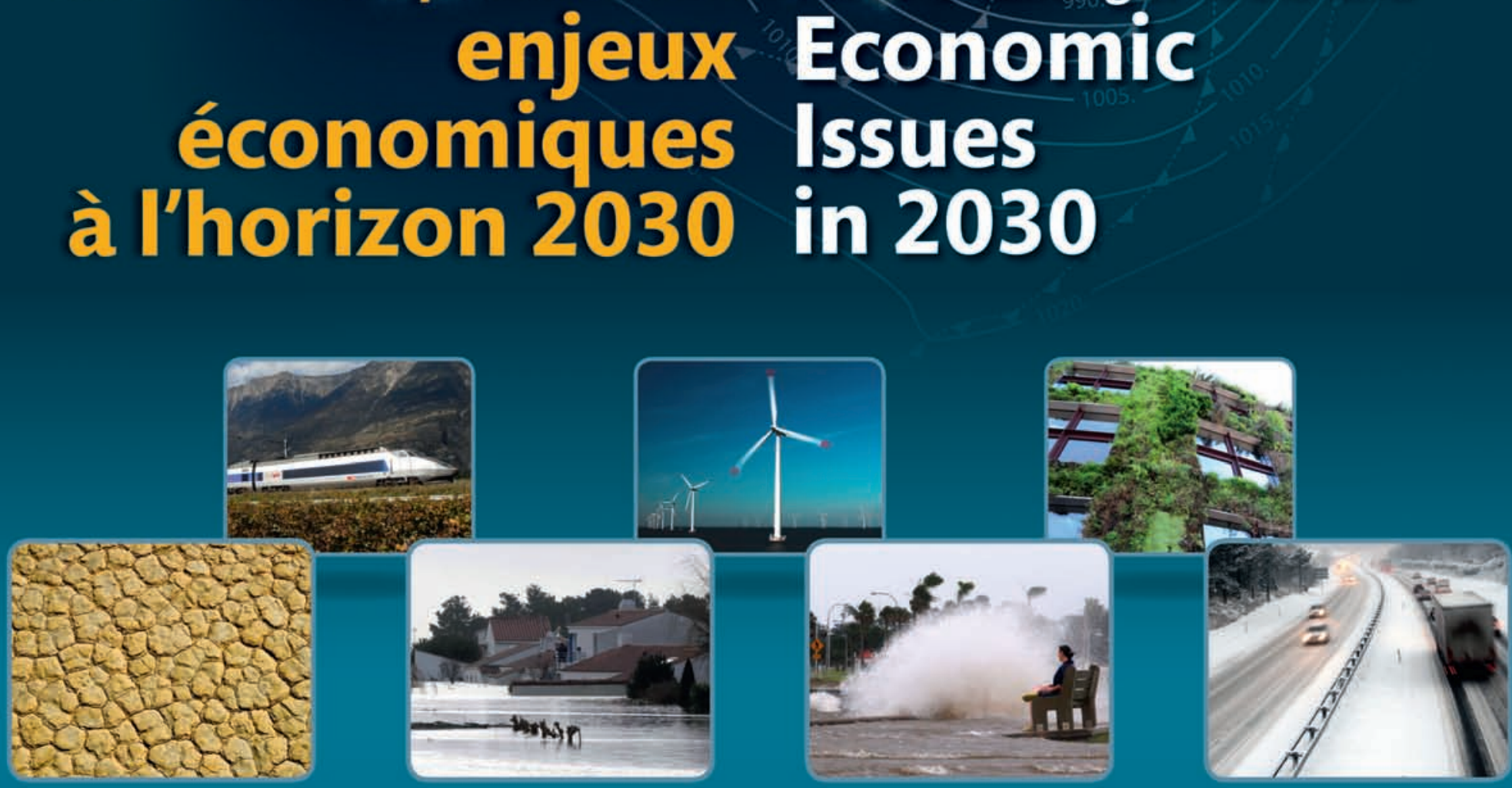

21 mars 2013 March 21, 2013

Conseil économique social et environnemental

9 place d'léna Paris $16^{\circ}$

\section{www.forumeteoclimat.com}

SOUS LE HAUT PATRONAGE DE

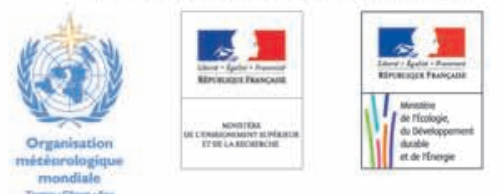

E플 ati - contur
SPONSORS «ARGENT "

ĐEIFFAGE
SPONSORS «OR

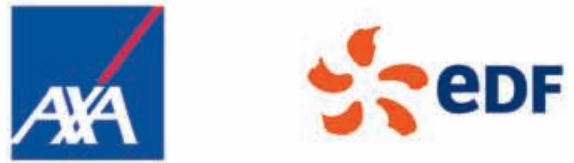

PARTENAIRES MEDIAS Press Clubstives

MEPLANETE 


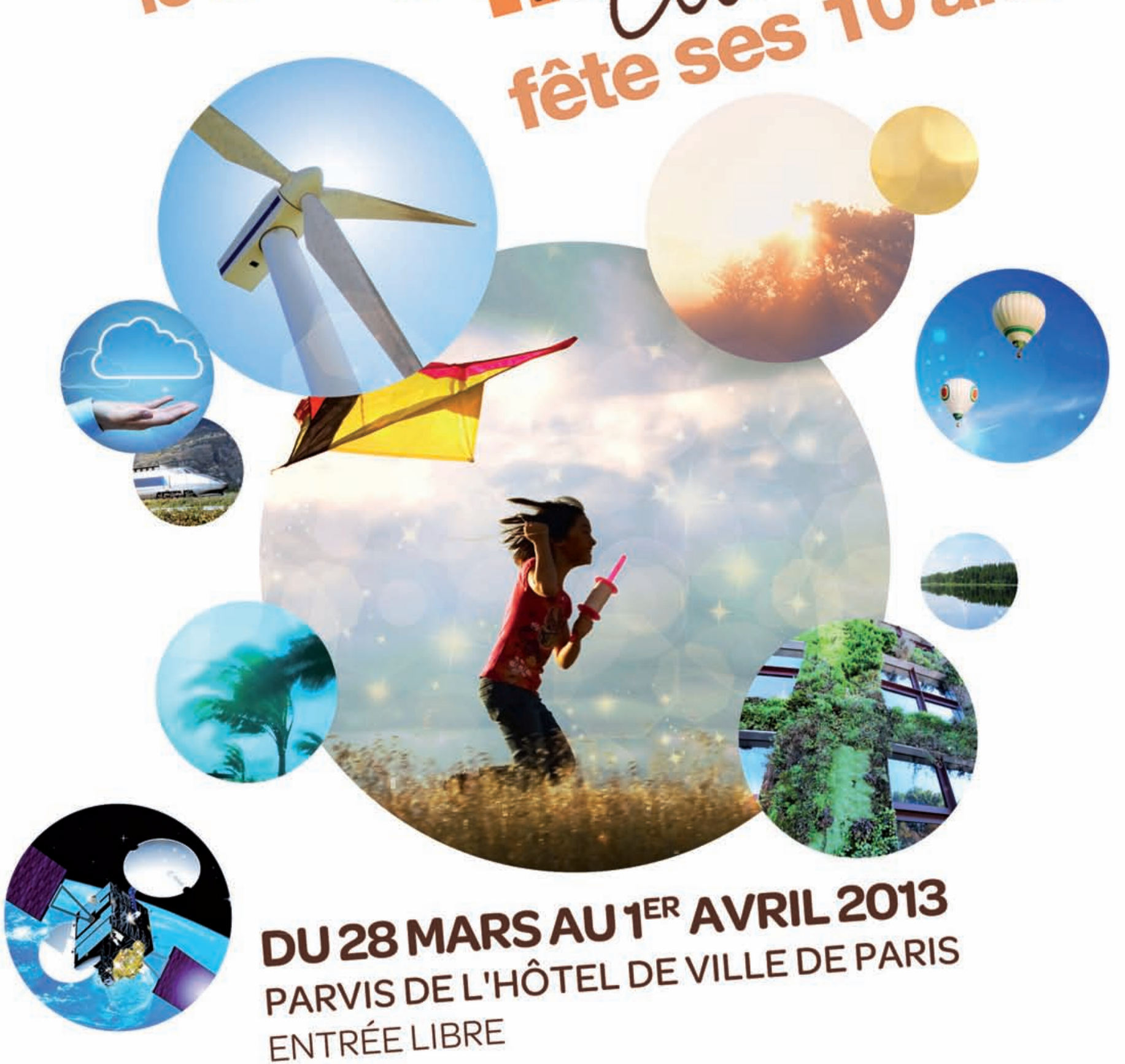

Animations - Ateliers - Débats - Spectacles www.forumeteoclimat.com Évènement co-organisé par Météo et Climat, Société météorologique de France

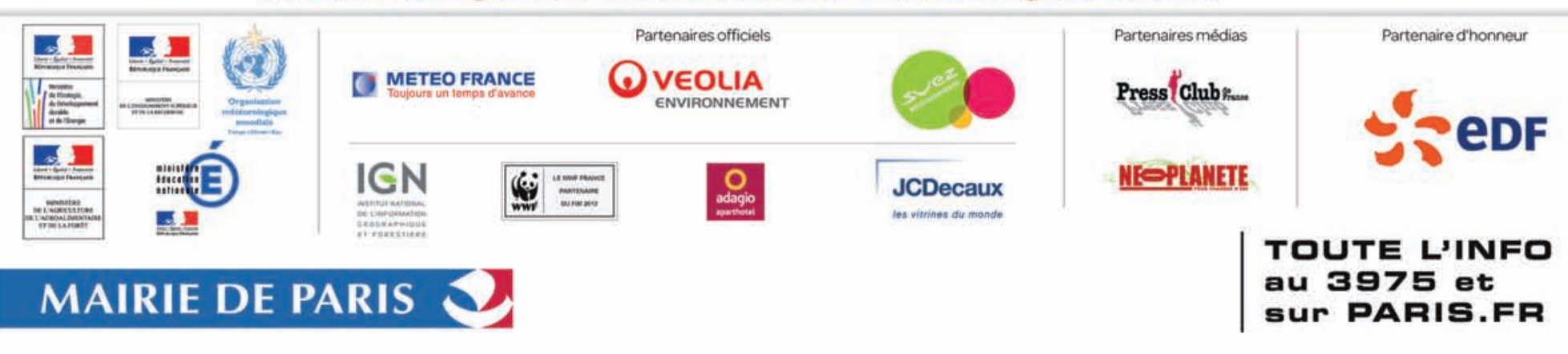

